\title{
Innovation Research on Elements of the Republican Period in Chinese History in Modern Tea Packaging Design
}

\author{
Xiaochen Geng ${ }^{1,2, *}$ Miaomiao Qiu $^{3}$
}

\author{
${ }^{1}$ School of Art, Nantong University, Nantong, Jiangsu, China \\ ${ }^{2}$ Fuzhou University, Fuzhou, Fujian, China \\ ${ }^{3}$ Xiamen Academy of Arts and Design, Fuzhou University, Xiamen, Fujian, China \\ *Corresponding author. Email: geng0617@163.com
}

\begin{abstract}
The elements of the Republican period in Chinese history were once regarded as a symbol of the old era, but in recent years, with the rise of the fashion of retro design, many designers pay more attention to the design of the Republican period. This paper discusses the value and application of design elements of the Republican period in Chinese history in tea packaging under the current commercial culture through literature analysis, case analysis and analogy. Chinese tea packaging design should not only be limited to the continuation of tradition, but also needs fresh vitality. The way to apply the packaging design elements of the Republican period in the current tea packaging design innovation is the focus of this paper.
\end{abstract}

Keywords: elements of Republican period in Chinese history, modern tea packaging, packaging design, innovation

\section{INTRODUCTION}

"Packaging design of the Republic of China" refers to the basic characteristics of public clothing, food, housing and transportation in the period of the Republic of China [1]. The literary and artistic phenomena in the Republic of China from 1912 to 1949 were praised as "the Renaissance of China" by design historians. The 1930s was the most brilliant era of design in the Republican period, when business and culture collided violently, eastern and western cultures merged, and creative and aesthetic expressions were extremely rich. Graphic design thoughts during this period basically completed the transformation of the modern art to the modern design thinking, and the mass aesthetic layer is also in line with the contemporary international design level [2].

During this period, the national enterprises seized the opportunity of government industry to save the country, drew lessons from foreign products such as Coca-Cola, perfume packaging and advertising forms, and integrated into the local culture, so as to package

*Funds: 2014, China National Social Science Foundation Art Project, Research of Chinese Pewter craft culture and its artistic active state inheritance, Project Number: 2014CG134, initial results;

2015, China Postdoctoral Science Foundation, Research about the Radiation and Inheritance of Chinese Pewter art in Southeast Asia, Project Number: 2015M570465, initial results. and convey visual information.

Chinese local cultural elements in packaging divides the boundary between domestic and foreign products, and the packaging uses traditional elements to establish emotional connection with the consumer audience, which implies that it conforms to the public's expectation of a better life in the future [3]. This also enlightens the development of modern tea packaging design, and it is necessary to find the essence of Chinese design culture and explore the intersection of traditional elements and current popular culture [4].

From the perspective of marketing, tea packaging is the formal product of tea brand. Against the background of consumption upgrading, Chinese tea brands need to use packaging forms in line with the trend of the times to enhance their added value [5]. It is also the most important starting point for this paper to study the tea packaging design of the Republic of China. It's necessary to draw on the experience of graphic design in the period of the Republic of China, to create national, contemporary and novel Chinese tea brand design. 


\section{Packaging Design elements OF REPUBLICAN PERIOD IN CHINESE HISTORY}

Packaging design elements in the Republican period mainly include:

- Diversified graphic forms;

- Font design with its own style;

- Innovative application of traditional colors.

The following three points are discussed:

\section{A. Diversified graphic forms}

In the period of the Republic of China, visual design began to focus on graphic and text, requiring graphics and text layout to complement each other. It's needed to make good use of local secular traditional patterns in decoration, to increase information interest and access to public attention. In order to promote goods, the national capitalists began to pay attention to the packaging of goods. At that time, when traditional concepts were still very strong, they created exquisite packaging art combining traditional culture with western culture [6]. In many coastal trading cities, national enterprises will strengthen their own brand awareness of trademarks. There are so many unique packages. The monthly calendar card advertisement drawn by artists has been used in graphic design of various industries [7]. Even the newspaper advertisement of that era, text, graph, and format also undergone artistic processing.

\section{B. Font design with its own style}

At that time, there was a lack of uniform font base. On the basis of Chinese calligraphy font, it also absorbed the characteristics of western font design, thus forming a distinctive artistic font style. The font is thick, the strokes are changeable, not deliberately pursuing balance, and the form is free.

\section{Innovative application of traditional colors}

In the period of the Republic of China, the color of the plane design is still using the traditional five-color splicing, the color brightness is low. This is closely related to the local Chinese traditional concepts and aesthetic interests at that time. Even a small matchbox at that time was full of the aesthetic taste of national design.("Fig. 1") The contrast of red, blue, yellow, green and orange created a lively and festival atmosphere, which is close to the lives of the people and extremely recognizable; however, it also conforms to the design criteria. When a brand or package only uses several colors as standard colors, it is more likely to reduce the memory cost of the brand and deepen the brand image into the field of consumer awareness.

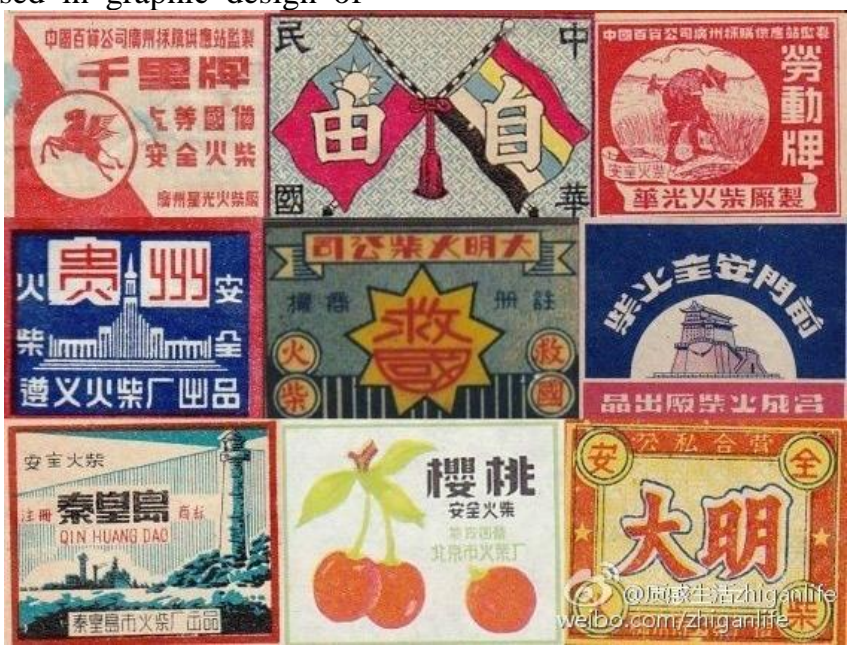

Fig. 1. Matchbox packaging in the Republican period.

\section{INNOVATION OF ELEMENTS OF REPUBLICAN PERIOD IN MODERN TEA PACKAGING DESIGN}

\section{A. Design status}

The design style of the Republican period in Chinese history was once regarded as a symbol of a period of history, but in recent years, with the rise of a. Source: https://huaban.com/pins/694984597/ the design style of the Republic of China restoring ancient ways, designers have paid more attention to the design of the Republican period. Nowadays, the design of the style of the Republic of China is widely used in the commercial design of all walks of life, which is not limited to the traditional commercial field. The design features summarized by many designers from the past design cases provide guidance for the application of the style of the Republican period in modern packaging 
design. With the rapid development of commercial design, the material application forms become more and more abundant. Derivative products extend the brand product line.

The packaging of goods in the style of the Republican period is getting more and more new with each passing day, which is the reproduction of modern national culture in the contemporary mass life aesthetics. It not only satisfies people's nostalgic psychology of exploring the sentiment of the Republican period in Chinese history, but also powerfully promotes the commodity publicity with the modern national culture. The application of retro and nostalgic elements brings new directions and ideas to the tea packaging design. In addition, the tea itself is rich in connotation, which greatly meets the diversified psychological needs of consumers and stimulates the nostalgic psychology. Meanwhile, it also deepens consumers understanding of tea as well as their understanding of tea[8]. ("Fig. 2")

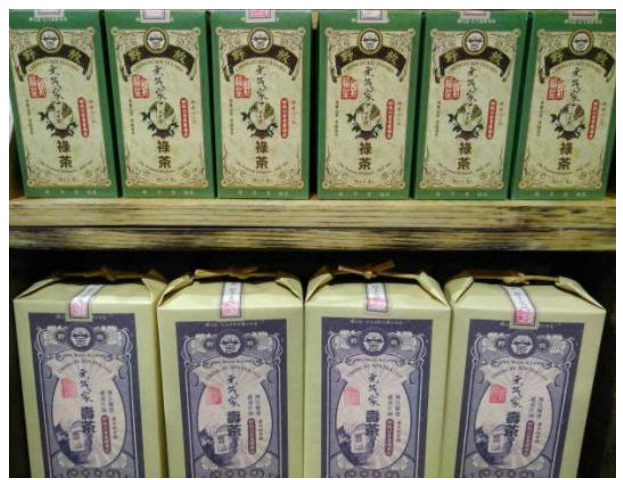

Fig. 2. The packaging of tea.

Source: Self-shooting

The elements of the Republic of China are applied in the modern tea packaging, and the western layout design of the Republican period of Chinese history and the traditional color with higher gray scale are mostly used for reference. Multifarious flower frame design and simple cowhide material paper set off each other. Mainly highlight the types and functions of products, so that the audience quickly access to product information. It can be seen that packaging design in the Republican period is still of great commercial and cultural value in terms of text, color, format and material design. Now, many domestic products are really taking the long history of the brand as a strong competitiveness, and are committed to shaping the long history of the brand image. In order to gain consumer trust, the imitation of the design characteristics of the Republican period is emerging in endlessly [9].

For example, Fu Pei, and Shanghai VIVE, Ye Fang Tea on the basis of the retro national wind bold innovation, but went out of the new people national wind road. PECHOIN, founded in Shanghai in 1931, has a history of 87 years as one of the leading cosmetics brands in China. PECHOIN has a strong Chinese traditional characteristics. The brand name " PECHOIN" means "birds paying homage to the phoenix", while "Ling" is homonymous with "Ling" (meaning "very good") in Shanghai dialect. This just caters to the people's vision of a better life. Based on the integration of eastern and western cultures, the establishment of its brand is also deeply influenced by historical trends. In the beginning of the founding, PECHOIN has set out to establish the image of the national brand, and put a variety of posters advertising in the streets of Shanghai at that time in every corner to expand brand publicity.

As shown in "Fig. 3", the poster design of PECHOIN reflects the graphic design features of the Republican period: the bold art fonts, the elegant women wearing cheongsam painted with brush and watercolor, the concise advertising language, the use of lace and the layout design of calendar all constitute the earliest image prototype of China's earliest cosmetic commercial brand. At that time, such brands as calendar were too numerous to list in the form of print advertising. Stars like Hu Die and Ruan Lingyu were the cover figures of these brands, and their own social publicity power promoted the sales of products. In 1940, PECHOIN cold cream, become a favorite of the upper class, song three sisters and other celebrities is the loyal audience of the product. The blue and yellow round iron box with Chinese and English bilinguals and the two lifelike yellow finches have also become the lasting memory of that generation of Chinese people. Even many post-90s still remember this old product commonly used by their elders in their childhood. And the small iron box that is still being produced, become the classic product of PECHOIN, which is still familiar with package and formula.

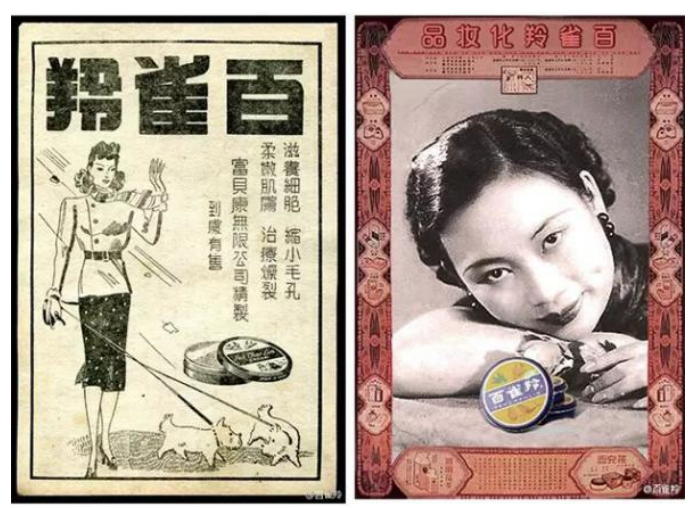

Fig. 3. The poster of PECHOIN CREAM.

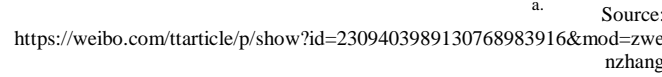

For the sake of innovation, PECHOIN walk out the new national tide brand road. In the initial stage of 
establishment, PECHOIN set out to establish its brand image and put various placard advertisements in every corner of the streets of Shanghai at that time to expand the publicity. As shown in "Fig. 3", the poster design of PECHOIN embodies graphic design elements of the Republic of China period: bold art font, elegant women wearing cheongsam painted with brush and watercolor, concise slogan, lace application and layout design of calendar plate.

PECHOIN has already realized from luxury to parity, from the classic to the tide of the positioning change, in order to adapt to the flexible business market. In order to change the young consumer's cognition of its brand, the tea packaging in the Republic of China wind, has "fun" interest, with "fun, fashion, personality" as the characteristics, the old things mixed with modern elements, not only evoke the feelings of the previous generation, but also with the young generation looking back in the past. HEYTEA and PECHOIN cross the border cooperation, the

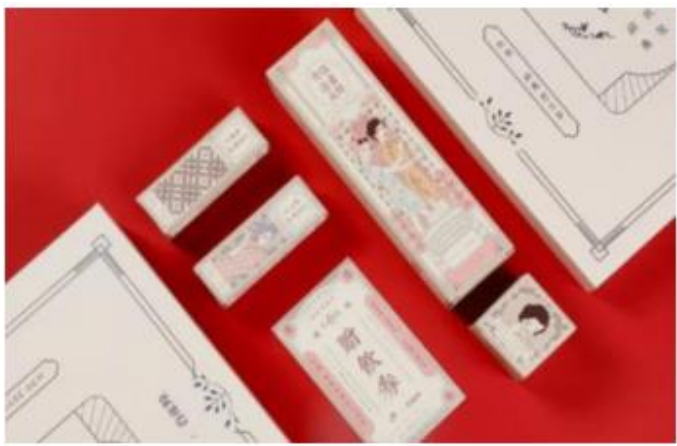

Fig. 4. The gift box of PECHOIN and Heytea.

As a modern tea brand, CHABAIDAO, a tea brand founded in Chengdu, is more traditional in packaging design style, using classic Chinese style. Its standard color and font are more retro. The design of the female image in cheongsam is more three-dimensional. The brand is positioned as: a wonderful time for Chinese combination of the two is based on the common part of the young female consumer groups, seemingly unrelated, but it is a symbiotic relationship, ultimately achieving a win-win situation. ("Fig. 4")

What is worth learning from is the sublation of the local traditional cultural elements, the real appeal of young consumers for popular tea drinks. The contrast between retro style and interesting linear vector figures actually forms a new fashion [10]. Two girls, A Xi and A Que, are used as IP images of HEYTEA and PECHOIN respectively. It is refreshing to use auxiliary graphics at two levels to weaken the connection between packaging auxiliary graphics and tea itself. Young people have a new understanding of tea: drinking tea can be fun. The design innovation of HEYTEA mainly lies in the simplification of packaging elements, the younger visual image, and the rejection of the homogeneity of packaging of similar products[11], which is the huge challenge that the tea industry will face in the long run in the future.

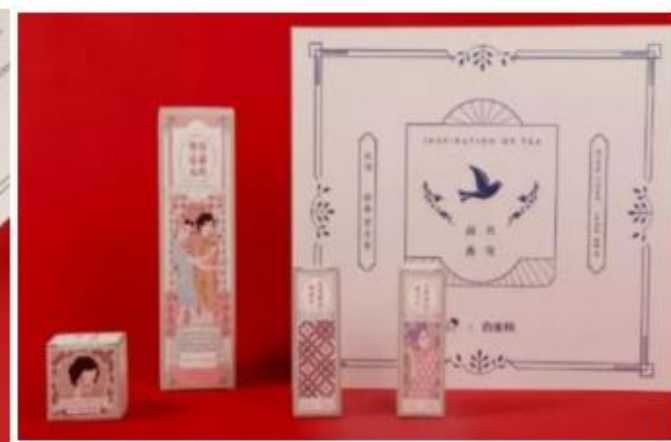

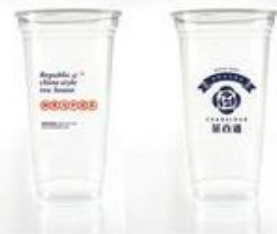

Fig. 5. The material used of CHABAIDAO

In the end, Ye Fang Tea, HEYTEA and CHABAIDAO, the three are typical of the design features applied to modern tea packaging in the period of the Republic of China. Their respective positioning is slightly different, resulting in differences in the final visual image. It can be seen from the Ye Fang Tea,
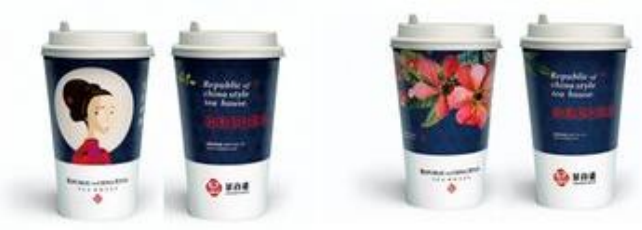
ene Based on China's local tea culture, the logo design uses tea elements to form the "hundred" shape flowers, which implied the brand concept "hundred flowers bloom, hundred tea fresh". In the use of materials, the form is flexible to shape the texture of unified products. 
blindly pursue the novel visual impression, but abandons the native design culture. This is also the completion of the packaging design task: to make the product easy to sell and save: to package the product in the most efficient and colorful way; to tell consumers what the characteristics of the product are, and to help consumers understand the product [12]. The design of the Republic of China realized the combination of penmanship and artistic calligraphy, pattern and logo, culture and market, nation and the world [13].

At present, the packaging design only stays in the old era of the packaging design elements copy, but rarely combined with the design features of the Republic of China and the use of tea culture packaging.

\section{B. Design value}

1) Innovation of design aesthetics in the Republic of China: Looking back at the Republic of China, what first came into our eyes were the free and lively fonts of fine arts, the exquisite calendar, the magazines and books of literati, etc. The design style of the Republic of China has experienced the precipitation of time, combined with western culture, exquisite and expressive, which still has great reference value for contemporary design. Not to mention the domestic folk art in this period in the use of artists, so that the period of the Republic of China graphic design shine brilliantly. The unique public aesthetic taste in the period of the Republic of China was based on the local cultural concept. The brilliance of design aesthetics in the Republic of China is worth studying whether it is commercial value or literary value.

2) Enriching the design forms of modern tea packaging: From the perspective of the overall background of tea industry brands, the market development trend of traditional tea industry is weak, but the popularity of tea brands relying on cultural marketing strategies such as small pot tea, HEYTEA is not decreased. In the current era of Internet consumption, these phenomenal tea products generate a huge amount of network traffic to promote the promotion and lead to the purchase frenzy of offline physical stores. Their practical significance provides a new idea on whether we can develop our nation's contemporary tea culture from the new image of tea packaging culture.

Under the general trend of consumer market upgrading, Chinese tea brands need to enhance their added value by means of reasonable packaging, shape a unique brand image, and actively adapt to the consumption characteristics of the times.

Tea packaging can't be separated from the physical and spiritual characteristics of tea itself, Chinese tea packaging design should be based on the core of local tea culture: harmony, quiet, pleasant and true, to reflect the beautiful character of tea [14]. Folk known as: 'open the door seven things, rice, cooking oil, salt, sauce and vinegar tea'. In the design of tea packaging, we should not only create the image of the tea environment, but also convey the image of Chinese tea as a kind of life. During the period of the Republic of China, packaging used its unique slang to publicize its advertising information. Tea is a theoretical category with great research value, which is not only related to botany, chemistry, culture, art and economy, but also closely related to people's life. The writing of advertising slogan tried to be concise and interesting, which was closer to the hearts of consumers and more powerful than any rhetoric. The slogan on the package is a mixture of rigorous and interesting style, but a sense of contrast.

\section{THE DESIGN CHARACTERISTICS OF THE REPUBLICAN PERIOD USED IN THE DESIGN PRACTICE OF MODERN TEA PACKAGING}

\section{A. The Republic of China packaging design features}

1) Characters of graphic design: The Republican period in Chinese history is a beautiful flourishing era. The women of that age are elegance and fashion, have the dignity and confidence which came from the blood. They also have the yearning for knowledge and a better life from the heart. During the period of the Republic of China, female figures were often used as the creation prototype in the designs, such as the watercolor calendar cards painted by various art museums. Therefore, it is more appropriate to refine the images of the characters in the period of the Republic of China to the intellectual women who wear cheongsam, step on high heels, and wear a bun with a slanting style. However, this figure needs to be modernized and recognized by the young group. In view of the needs of the consumer audience and the current consumer market, it is impossible to transfer the female image of the Republic of China. Instead, it finally uses the mellow lines to draw the female figure illustration image after artistic processing. People always know the wisdom of life, so that they enjoy the fun of life. This is exactly the life attitude that contemporary women need. Therefore, the design prototype is based on the wonderful instant image of women in cheongsam drinking tea.

2) Color extraction: Due to the limitations of printing technology, color printing was mainly composed of solid colors at that time. Red, black, yellow, blue and other colors were the main popular colors. The color brightness was slightly pink and dark, 
so the color matching showed a strong retro style [15]. A matchbox, also can be full of national aesthetic taste. Red, blue, yellow, green and orange colorful set off each other, creating a lively and festive keynote. Colors that are close to people's lives and highly recognizable. At the same time, people only using a few colors as standard colors in line with the design guidelines. Designers reduce the brand memory cost so that the brand image go deep into consumer awareness field. The color of visual design in the period of the Republic of China is mainly characterized by festival, flowery and rich to cater to the people's yearning for a better life [16].

3) Representation of graphic image: As one of the elements of packaging design, graphics play an important role in shaping brand image and conveying product information, in addition to the basic role of auxiliary decoration. The tea packaging graphics can not be separated from the physical characteristics and spiritual characteristics of the tea itself, Chinese tea packaging design should be based on the core of the local tea culture: harmony, quiet, pleasant, true to reflect the good quality of the tea. The folk has long been known as: 'opening the door seven things, daily necessities, rice, oil, salt, sauce, vinegar and tea'.

In the design of tea packaging graphics, we should not only aim to create an image of tea environment, but also to convey that today's Chinese tea is a life-style image of tea, rather than a connotative form of etiquette. The graphics of tea mountain, tea garden, tea masters and tea set on the package are intended to convey the image of tea products with cordial life atmosphere. Therefore, the brushstroke expression is free with the nature rather than the pursuit of perfect sense of form.

\section{B. Design scheme}

By studying the uniqueness of design style in the period of the Republic of China and the marketing characteristics of contemporary popular tea culture, this paper makes a new attempt on tea packaging design by using design language and linking the two cultures. In the form of visual design in the period of the Republic of China, contemporary tea packaging is used as a medium to convey the tea drinking culture of the new era. On the color reference of the Republic of China period of lower brightness of orange and blue, so that the design has a sense of age. The large area uses the blue white technique on the one hand, on the other hand, the contrast obvious light and shade relations produces the tea brand packaging which has the unique retro charm. ("Fig. 6")

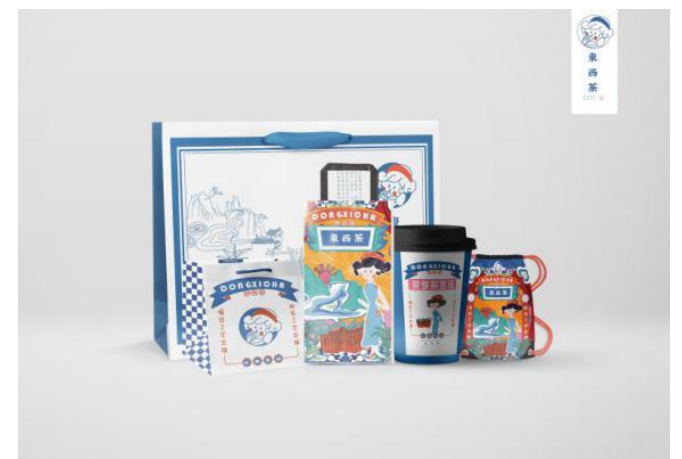

Fig. 6. Packaging design.

Drawing lessons from newspaper advertisements of the 1930s, artistic processing was carried out on the forms of text, graphics and layout. Tea culture is not old-fashioned preaching a way to go, just as the packaging of the Republic of China with its unique slang way to promote its advertising information. The writing of advertising slogans should to be concise and interesting. The introduction closes to the hearts of consumers is more powerful than any rhetoric. Tea is a theory category of great research value, which is not only related to botany, chemistry, culture, art and economy, but also closely related to people's life. When the slogan on the package is a mix of rigorous and interesting style, it creates a sense of unexpected contrast. China's tea and design culture have a long history. They have never died out and will be passed down from generation to generation.

\section{CONCluSION}

\section{A. Design summary}

In this paper, the characteristics of packaging design in the period of the Republic of China are explored, and the visual design materials of the contemporary style of the Republic of China are used for reference. Packaging design in the Republic of China period still has a strong penetration, because they reflect the secular culture and popular advertising culture, and those are the aesthetic taste of life, never hung high. Some brands such as HEYTEA can design milky tea packaging with a playful and interesting attitude to achieve sales results. But the real Chinese tea culture itself cannot be separated from the tea itself. The more social civilization develops in the rolling tide of the times, the more we cannot forget the essence of the past culture. Tea packaging "DONGXI TEA" is named for the tea packaging in the period of the Republic of China as the result of the collision of east and west cultures. The logo design is composed of graphics and fonts. The fonts refer to the design form of the fine arts in the Republic of China, and strokes of Chinese character are heavy. In this study, tea packaging designed in the form 
of newspapers and calendar cards of the Republic of China was used to spread tea culture to young consumers, which is a new way to explore the combination of Chinese tea culture and modern tea commercial economy.

\section{B. Deficiencies and limitations}

There are still many deficiencies in the application of design features in the period of the Republic of China to the innovative design of modern tea packaging, which are mainly summarized as follows:

The change of time is not conducive to research, sorting out and investigation. People's set thinking on the design concept in the Republic of China also makes the tea package design in the Republic of China too limited.

The design of the Republic of China from 1912 to 1949 is a big category, which cannot be summarized in a word or two. In this paper, only a few representative characteristics were selected to discuss the application of the design features of the Republic of China in the modern tea packaging design. Therefore, the value of the characteristics of the packaging design of the Republic of China in the application of tea packaging design was still relatively limited.

\section{References}

[1] Li Feng. Application of mtime in modern packaging design [J]. Packaging engineering, 2014, 35(22):93-97.

[2] Zhou Ren. Stamps of the late Qing dynasty and the republic of China: aesthetic style of a kind of "banknote" — on modern Chinese stamp design from the perspective of graphic design history [J]. Shanghai culture, 2019(02):83-92+126.

[3] Peng Yuhan. Packaging design of cosmetics in the republic of China [J]. Popular art, 2018(12):87-88.

[4] Yang Qing, Liu Xin. Inspiration of Japanese packaging design to Chinese packaging design $[\mathrm{J}]$. Art education research, 2016(01):68-69.

[5] Xu lu. From product packaging to brand packaging — strategies for packaging design of Chinese tea brands in the context of consumption upgrading [J]. Decoration, 2018(02):30-36.

[6] Zhao Shaoyin. Inspiration of the suitability of packaging design in modern China - a case study of tooth powder packaging in the republic of China [J]. Chinese art, 2018(05):50-55.

[7] Gu Yan. Packaging design methodology of the republic of China [J]. Modern decoration (theory), 2016(07):106.

[8] Wang Juan, Hu Xiaoyan. Artistic features of commodity packaging design in Guangdong during the republic of China [J]. Art design research, 2015 (03): 75-81.

[9] Yang lei. Research on the influence of "west wind spreading east" on the decorative art style of commercial art in the period of the republic of China [D]. Kunming university of science and technology, 2017

[10] Han Xing. A study on the youth design of tea packaging [D]. Liaoning normal university, 2017.

[11] Zhang Wenlian. Chinese tea culture and modern tea packaging design [D]. Soochow University, 2007.
[12] Giles calver. What is packaging design? [M]. China Youth Publishing House, 2006.

[13] Liu Ying. A study of visual symbols in the republic of China [D]. JiangNan University, 2008.

[14] Zhang Yan. Research on the cultural marketing means of tea brands [J]. FuJian Tea, 2016, 38 (11): 46-47.

[15] $\mathrm{Hu}$ lanlan. Research and application of food packaging design in Shanghai in the early republic of China [D]. Anhui University, 2016.

[16] Yuan Fang. Exploring the visual beauty of calligraphy in the period of the republic of China [D]. ZheJiang University of Science and Technology, 2016. 